\title{
Recycling Effects of Residual Slag after Magnetic Separation for Phosphorus Recovery from Hot Metal Dephosphorization Slag
}

\author{
Kazuyo MATSUBAE-YOKOYAMA, ${ }^{1)}$ Hironari $\mathrm{KUBO}^{21}$ and Tetsuya NAGASAKA ${ }^{11}$ \\ 1) Graduate School of Environmental Studies, Tohoku University, Sendai 980-8579 Japan. \\ 2) Formerly Graduate School of Environmental Studies, Tohoku University, Sendai 980-8579 Japan, Now at Asahi Pretec Corp., \\ Kobe 651-2241 Japan.
}

(Received on August 20, 2009; accepted on September 18, 2009; originally published in Tetsu-toHagané, Vol. 95 (2009), No. 3, pp. 306-312)

\begin{abstract}
In a previous study, the authors found that phosphorus exhibits remarkable segregations in industrial hot metal pretreatment slag where it exists as a $\mathrm{Ca}_{3} \mathrm{P}_{2} \mathrm{O}_{8}-\mathrm{Ca}_{2} \mathrm{SiO}_{4}$ solid solution together with a $\mathrm{FeO}-$ $\mathrm{CaO}-\mathrm{SiO}_{2}-\mathrm{MnO}-\mathrm{MgO}$ matrix. Since the magnetic property of each phase is significantly different, it is possible to separate the phases with the aid of a superconducting strong magnetic field. By applying a strong magnetic field of 0.5 to $2.5 \mathrm{~T}$ to the crushed slag, more than $60 \%$ of the concentrated phosphorus phase in the slag was recovered. If most of the phosphorus can be removed from the slag, the residual slag will comprise $\mathrm{FeO}-\mathrm{CaO}-\mathrm{SiO}_{2}-\mathrm{MnO}-\mathrm{MgO}$ with less $\mathrm{P}_{2} \mathrm{O}_{5}$, and thus may be recycled to iron- and steel-making processes, such as sintering, hot-metal desiliconization, and hot-metal dephosphorization processes. In the present work, the recycling effect of subjecting the residual slag to the dephosphorization process was simulated based on a mass balance calculation. A significant reduction in total slag generation and $\mathrm{CaO}$ input was demonstrated by the mathematical model considering phosphorus recovery and recycling of residual slag as a dephosphorization agent. Using the waste input-output model, it was shown that phosphorus recovery from dephosphorization slag and the recycling of residual slag in a hot-metal dephosphorization process have potentially great environmental and economic benefits.
\end{abstract}

KEY WORDS: multi-phase flux; hot metal pretreatment; dephosphorization; slag recycling; waste input-output analysis.

\section{Introduction}

Phosphorus is an element that plays an important role in both nature and human economic activity. In industry, phosphorus is primarily used as a constituent of fertilizers that support food production and as component of materials, such as polyphosphoric acid, that are used in many products. Great strategic importance is attached to phosphorus as a raw material in fertilizer production; this is because fertilizer production is directly related to a boost in food production and to the production of grain for the manufacture of bioethanol. In Japan, which depends on foreign countries for phosphorus resources, it is already becoming extremely difficult to secure phosphorus; indeed, the secure, stable supply of phosphorus is an urgent issue all over the world. ${ }^{1-4)}$

In contrast to the above issues of phosphorus supply, phosphorus is also a typical detrimental impurity in steel materials and, hence, must be removed from molten iron in the steel industry. Previous papers ${ }^{3,5}$ clarified the macrodomestic material flow of phosphorus within Japan and showed that, on the basis of the data in 2002, about $97 \mathrm{kt}-\mathrm{P}$ of phosphorus was generated as part of steel-making slag from hot metal produced by blast furnace. This amount is approximately equivalent to the total amount of phosphorus imported into Japan in the form of phosphate rock. More specifically, in hot-metal dephosphorization slag, which is a typical multi-phase slag, phosphorus generally forms $3 \mathrm{CaO} \cdot \mathrm{P}_{2} \mathrm{O}_{5}-2 \mathrm{CaO} \cdot \mathrm{SiO}_{2}$ in the solid solution (phosphorus enriched phase); it contains little iron and it can be dispersed by means of $\mathrm{CaO}-\mathrm{SiO}_{2}-\mathrm{Fe}_{\mathrm{t}}$-based matrix phases. ${ }^{6}$ ) In the light of this knowledge, the authors experimented with separation and recovery of the phosphorus enriched phase using a high magnetic field gradient generated by superconducting magnets. The result showed that more than $60 \%$ of the phosphorus enriched phase was recovered. ${ }^{7)}$

In existing steel-making processes, approximately 14 million tons of slag is generated from blast furnace hot metal runner, torpedo cars, BOF, ladles, etc. ${ }^{8)}$ A considerable amount of such slag is reused as building materials. However, although trace amounts of phosphorus or manganese contained in raw materials, such as iron ore and coke, are highly concentrated into the slag through the steel-making process, which is an oxidation refining process, utility value of phosphorus or manganese as an elemental resource is essentially none. Building materials for roads and other structures certainly do not constitute high-valueadded applications and so, for the steel industry, the development of new uses of steel-making slag is an important issue as well as finding ways to reduce the total amount of 
Table 1. Composition of dephosphorization slag used in this study. The slag consists of phosphorus-enriched phase (P-phase) and matrix phase (M-phase).

\begin{tabular}{c|c|c|c|c|c|c|c}
\hline & \multicolumn{5}{|c|}{ composition (\%) } & \multirow{2}{*}{$\begin{array}{c}\text { phase ratio } \\
(\%)\end{array}$} \\
\cline { 2 - 7 } & $\mathrm{Fe}_{\mathrm{t}} \mathrm{O}$ & $\mathrm{P}_{2} \mathrm{O}_{5}$ & $\mathrm{CaO}$ & $\mathrm{SiO}_{2}$ & $\mathrm{MnO}$ & $\mathrm{MgO}$ & \\
\hline average & 18.1 & 6.6 & 45.9 & 20.3 & 2.5 & 5.5 & \\
\hline P phase & 0.6 & 11.8 & 60.5 & 26.7 & 0.2 & 0.3 & 56.2 \\
\hline M phase & 40.5 & 0.2 & 27.2 & 12.0 & 5.7 & 12.5 & 43.8 \\
\hline
\end{tabular}

generated slag.

In these circumstances, if phosphorus can be recovered from dephosphorization slag by the method proposed in recent papers, ${ }^{5,7)}$ it is possible that the recovered substances can be effectively used as new resources of phosphorus and that the steel industry will contribute to solving the tight supply-demand problem for phosphorus. Moreover, the residual slag that remains after phosphorus recovery has a significantly decreased phosphorus concentration and primarily components $\mathrm{FeO}-\mathrm{CaO}-\mathrm{SiO}_{2}(-\mathrm{MnO}-\mathrm{MgO})$. Subsequently, by recycling the residual slag in upstream processes, it may be reused as a refining flux, which has a higher added value than building materials. In addition, there is also a possibility that the overall amount of generated slag will be greatly reduced.

This paper quantitatively analyzes the results in the case where residual slag was recycled in upstream processes based on the assumption that the magnetic separation method was applied to hot-metal dephosphorization slag. First, the influence of residual slag recycling on the required input of fluxes and the overall amount of generated slag was calculated based on mass balance; then, the economic ripple effects and the effects in reducing environmental loads of phosphorus recovery and residual slag recycling were analyzed by using a waste input-output model. ${ }^{9,10)}$

\section{Examined Processes}

In the magnetic separation process proposed in previous papers, ${ }^{5,7)}$ compositions of recovered phosphorus concentrate and residue vary according to average compositions of slag, cooling methods, and magnetic separation methods; each of these factors is not determined uniquely. Although clarification of the relationships among them is an issue for future study, the data obtained in previous papers were used here in order to quantitatively measure the recycling effects of residual slag after magnetic separation. Table 1 shows average compositions of slag, concentrations of a phosphorus enriched phase ( $\mathrm{P}$ phase) and a matrix phase ( $\mathrm{M}$ phase), and ratios of the two phases, as used in a previous paper. ${ }^{7)}$ The magnetic separation method is one in which the $\mathrm{P}$ phase and $\mathrm{M}$ phase shown in Table 1 are separated into an unmagnetized substance and a magnetized substance, respectively. As seen in Table 1, if the two phases are sufficiently separated, the magnetized substance, or phosphorusremoved residue, would be composed of $\mathrm{FeO}-\mathrm{CaO}-\mathrm{SiO}_{2}-$ $\mathrm{MnO}-\mathrm{MgO}$ and could then be recycled into upstream processes of refining, such as sintering, hot-metal desiliconization, and hot-metal dephosphorization as shown in

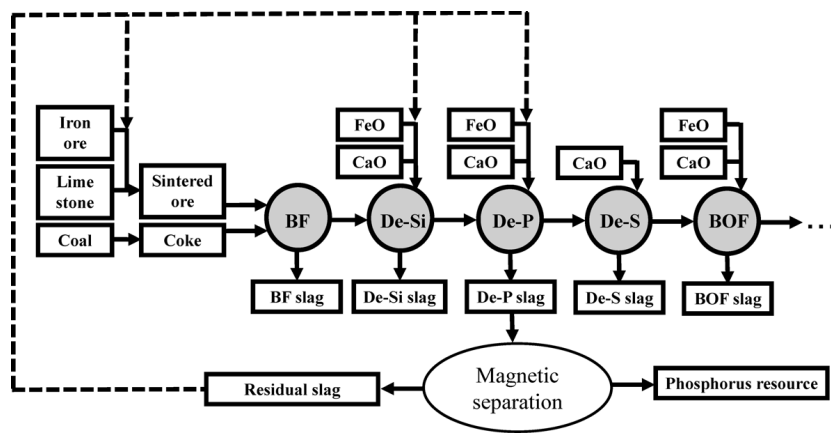

Fig. 1. Schematic process flow diagram of the conventional $\mathrm{BF}-\mathrm{BOF}$ steelmaking process including possible recycling pathways for residual slag after the magnetic separation of dephosphorization slag for phosphorus recovery. ${ }^{5,7)}$
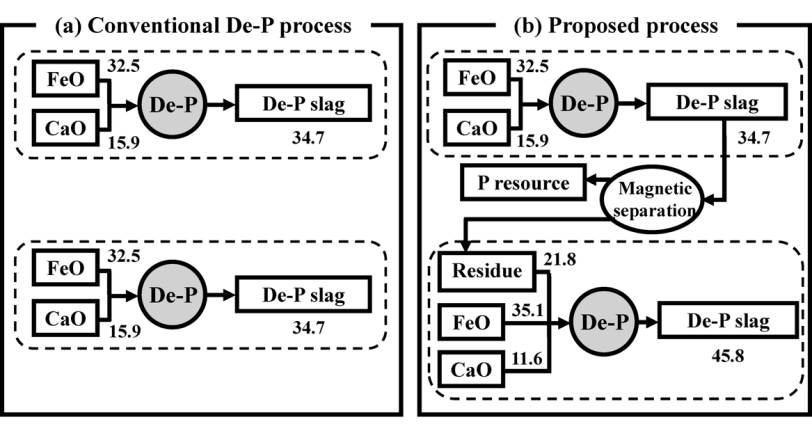

unit: $\mathrm{kg} / \mathrm{THM}$

Fig. 2. Schematic process flow diagrams of (a) conventional hot metal dephosphorization process and (b) proposed process of residual slag recycling.

Fig. 1. The authors ${ }^{11,12)}$ indicated that, in hot-metal dephosphorization slag, an MnO-rich $\mathrm{MnO}-\mathrm{FeO}-\mathrm{CaO}-\mathrm{MgO}-$ based solid solution may appear in the $\mathrm{M}$ phase depending on operating conditions. However, this study assumed that the hot-metal dephosphorization slag basically consisted of two crystalline phases, as shown in Table 1 . This study then analyzed the ripple effects of recycling the residual slag after magnetic separation in a dephosphorization process on the required input of dephosphorization agents and the amount of discharged slag.

Figure 2 shows the examined processes. First, we consider the case where $\mathrm{FeO}$ and $\mathrm{CaO}$ are charged into a first charge of hot metal pretreatment, as normally happens, and dephosphorization slag is generated. The discharged dephosphorization slag, rather than being disposed of, undergoes magnetic separation, and the $\mathrm{P}$ phase is recovered from it. The residual slag is charged with the required amounts of $\mathrm{FeO}$ and $\mathrm{CaO}$ to maintain dephosphorization 
power and is fully recycled as a dephosphorization agent for a second charge. After dephosphorization with a second charge, the discharged slag is disposed of. The process in this case involves two charges of hot metal, and therefore it is compared with two corresponding cycles of the conventional dephosphorization process. The inputs of $\mathrm{FeO}$ and $\mathrm{CaO}$ and the amount of discharged slag were examined quantitatively in the two processes, (a) and (b).

\section{Calculation Method}

\subsection{Mass Balance in Conventional Dephosphorization Treatment}

This study assumes that, with reference to actual values obtained from iron and steel-making factories, hot metal compositions change before and after the dephosphorization process, as shown in Table 2, and slag with the composition described in Table 1 is discharged from the hot-metal dephosphorization process of the first charge. On the assumption that only stoichiometric oxidation reactions of the following four constituents proceed between slag and metal, and that loss by scattering, vaporization, etc. does not happen, the amount of slag generated from the first charge can be calculated from changes in the hot metal composition shown in Table 2 and the mass balance.

$$
\begin{aligned}
& 2[\mathrm{P}]+5(\mathrm{FeO})+3(\mathrm{CaO})=\left(3 \mathrm{CaO} \cdot \mathrm{P}_{2} \mathrm{O}_{5}\right)+5 \mathrm{Fe}(\mathrm{l}) \ldots . .(1) \\
& {[\mathrm{Si}]+2(\mathrm{FeO})=\left(\mathrm{SiO}_{2}\right)+2 \mathrm{Fe}(1) \text {. }} \\
& {[\mathrm{Mn}]+(\mathrm{FeO})=(\mathrm{MnO})+\mathrm{Fe}(\mathrm{l})} \\
& {[\mathrm{C}]+(\mathrm{FeO})=\mathrm{Fe}(\mathrm{l})+\mathrm{CO}(\mathrm{g}) \text {. }}
\end{aligned}
$$

Square brackets and parentheses indicate constituents in hot metal and in slag, respectively, and all iron oxides in the slag are regarded as $\mathrm{FeO}$ with a stoichiometric composition to simplify calculations. $\mathrm{MgO}$ is assumed to elute from refractories of a furnace wall to become the average concentration indicated in Table 1. As a first approximation, heat balance is ignored. In calculations from this point on, the generated amount of slag and the input of fluxes will be expressed as a unit per ton of hot metal (THM).

To check the dephosphorization power of slag, an empirical formula of phosphorus distribution in the hot-metal pre-

Table 2. Calculation of hot metal composition before and after the dephosphorization process.

\begin{tabular}{l|c|c|c|c|c}
\hline & \multicolumn{5}{|c}{$[$ mass\%] } \\
\cline { 2 - 6 } & $\mathrm{C}$ & $\mathrm{Si}$ & $\mathrm{Mn}$ & $\mathrm{P}$ & $\mathrm{S}$ \\
\hline before de-P & 4.40 & 0.15 & 0.25 & 0.12 & 0.03 \\
\hline after de-P & 4.20 & trace & 0.18 & 0.02 & 0.03 \\
\hline
\end{tabular}

treatment process, proposed by Ogawa et al., ${ }^{13)}$ was applied in this study. The formula by Ogawa et al. is shown in Eq. (5).

$$
\begin{aligned}
& \log (\operatorname{mass} \% \mathrm{P}) /[\operatorname{mass} \% \mathrm{P}] \\
& =2.5 \log (\operatorname{mass} \% \text { T.Fe })+0.0175\{(\operatorname{mass} \% \mathrm{CaO}) \\
& +0.25(\operatorname{mass} \% \mathrm{MgO})\}+7710.2 / T-8.55 \\
& +(105.1 / T+0.0723)[\operatorname{mass} \% \mathrm{C}] \text {. }
\end{aligned}
$$

The slag composition used to derive the equation is within 0.9 to 2.5 of basicity, 15 to 50 mass $\%$ of $\mathrm{CaO}$ concentration, and 10 (high basicity) to 45 mass\% (low basicity) of $\mathrm{FeO}$ concentration. The slag examined in this study is within the available range of Eq. (5) and is shown in Table 1. In Eq. (5), substituting $T=1573 \mathrm{~K}$ (temperature of dephosphorization treatment) and the values of slag composition shown in Table 1 yields 0.002 mass $\%$ of phosphorus concentration in hot metal. From this result, it is confirmed that the slag can adequately attain 0.02 mass $\%$-P in hot metal, which is the phosphorus level after dephosphorization shown in Table 2.

\subsection{Composition and Generated Amount of Residual Slag}

In dephosphorization treatment after residual slag recycling, that is, in a second dephosphorization in the process of Fig. 2(b), not only residual slag after magnetic separation but also $\mathrm{FeO}$ and $\mathrm{CaO}$ are charged as dephosphorization agents. Although it is natural that the composition and generated amount of residual slag should vary according to the properties of dephosphorized slag used for magnetic separation treatment and efficiency of the magnetic separation, it is desirable that substances recovered by magnetic separation contain a substantial amount of phosphorus, for the purposes of recovering phosphorus resources and effective recycling of residual slag. Therefore, the composition and the generated amount of residual slag was set based on the data (Table 3) in a previous paper. ${ }^{7}$ This data was obtained from a magnetic separation experiment in which slag composed as described in Table 1 was used, the magnetic field strength was $2.5 \mathrm{~T}$, and the number of separation path was 5. More specifically, under these conditions the phosphorus recovery ratio was approximately $60 \%$ and the mixing ratio of the $\mathrm{M}$ phase into the $\mathrm{P}$ phase was approximately $8 \%$. As

\begin{tabular}{|c|c|c|c|c|c|c|c|c|c|}
\hline & \multirow{2}{*}{$\begin{array}{l}\text { mass ratio against } \\
\text { initial slag (\%) }\end{array}$} & \multirow{2}{*}{$\begin{array}{c}\text { ratio against initial } \\
\text { P phase (\%) }\end{array}$} & \multirow{2}{*}{$\begin{array}{c}\text { ratio against initial } \\
M \text { phase }(\%)\end{array}$} & \multicolumn{6}{|c|}{ composition (mass\%) } \\
\hline & & & & $\mathrm{Fe}_{t} \mathrm{O}$ & $\mathbf{P}_{2} \mathbf{O}_{5}$ & $\mathrm{CaO}$ & $\mathrm{SiO}_{2}$ & MnO & MgO \\
\hline Recovered slag & 37.2 & 60 & 8 & 4.4 & 10.7 & $\mathbf{5 7 . 3}$ & 25.3 & 0.8 & 1.4 \\
\hline Residual slag & 62.8 & 40 & 92 & 26.2 & 4.4 & 39.1 & 17.3 & 3.7 & 8.1 \\
\hline
\end{tabular}
shown in Table 1 and Fig. 3, this slag consists of $56.2 \%$ of the $\mathrm{P}$ phase and $43.8 \%$ of the $\mathrm{M}$ phase; therefore, the residual slag generated under this condition should be a mixture of $40 \%(=100-60 \%)$ of the P phase and $92 \%(=100-8 \%)$ of the $\mathrm{M}$ phase. The composition of the residual slag was measured as shown in Table 3. The amount of slag gener-

Table 3. Composition of the recovered and residual slags after magnetic separation process for phosphorus recovery. ${ }^{7)}$ 
ated can be estimated from the amount of slag discharged from a first charge, which can be obtained by the procedure described in Sec. 3.1. In this manner, if the constituent phases of the slag are known, the composition and the generated amount of residual slag can be expressed in terms of two parameters: the phosphorus recovery ratio and the residual rate of the $\mathrm{P}$ phase. The residual rate of the $\mathrm{P}$ phase was defined as the ratio in weight of the amount of phosphorus remaining in the residue to the amount of phosphorus existing in the initial dephosphorized slag, which is a subject of phosphorus recovery, and expressed as $\varepsilon$.

\subsection{Mass Balance in Dephosphorization Treatment Using Residual Slag}

Because the residual slag does not contain sufficient $\mathrm{FeO}$, which is an oxidizing agent, and cannot promote reactions described in Eqs. (1) to (4) to the desired concentrations, additional charges of $\mathrm{FeO}$ and $\mathrm{CaO}$ are required. The amounts of additional charges of $\mathrm{FeO}$ and $\mathrm{CaO}$ and the discharged amount of slag can be obtained by setting the amounts of these additional charges of $\mathrm{FeO}$ and $\mathrm{CaO}$ as variables and, in the same manner as described in Sec. 3.1, by simultaneously solving for changes of hot metal composition, initial composition of residual slag, mass balance in Eqs. (1) to (4), and Eq. (5) under constraints described below. In this calculation, slag composition was calculated so that $[\mathrm{mass} \% \mathrm{P}]$ calculated from Eq. (5) could become 0.02 or less; that is, the generated slag would satisfy $0.02 \mathrm{mass} \%$ of final phosphorus concentration in hot metal. To prevent the final composition range of slag from deviat-

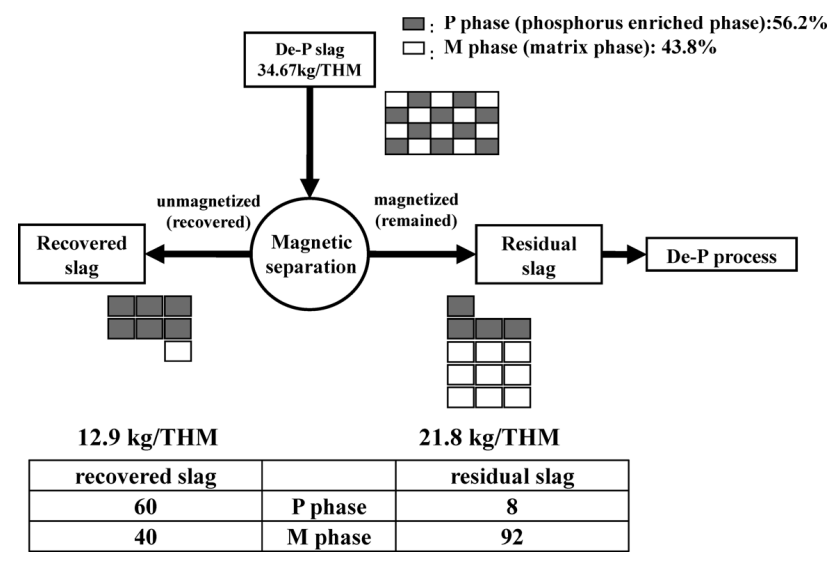

Fig. 3. Schematic process flow diagram of the magnetic separation of dephosphorization slag for phosphorus recovery, ${ }^{5,7)}$ showing the phase ratio of phosphorus-enriched phase (P-phase) and matrix phase (M-phase) in the recovered slag and residual slag. ing greatly from the experimental composition provided by Ogawa et al. ${ }^{13)}$ and from composition ranges of dephosphorized slag in actual operation, the final basicity of slag, (mass $\% \mathrm{CaO}) /\left(\operatorname{mass} \% \mathrm{SiO}_{2}\right)$, was fixed at 2.5 ; further, the $\mathrm{CaO}$ and $\mathrm{FeO}$ concentrations were limited to within 15-50 mass \% and 15-32 mass \%, respectively. In addition, the upper limit of $\mathrm{P}_{2} \mathrm{O}_{5}$ concentration in the slag was set as 7 mass \% because phosphorus in slag may return to hot metal if the concentration of $\mathrm{P}_{2} \mathrm{O}_{5}$ in slag increases drastically. Heat balance and reaction rate were not taken into consideration.

\section{Results and Discussions}

\subsection{Reduction of the Amounts of Charged Fluxes and the Amount of Discharged Slag}

The amount of slag produced in the first charge in the conventional dephosphorization process is summarized in Table 4. The input of $\mathrm{FeO}$ and $\mathrm{CaO}$ were found to be $32.5 \mathrm{~kg}-\mathrm{FeO} / \mathrm{THM}$ and $15.9 \mathrm{~kg}-\mathrm{CaO} / \mathrm{THM}$, respectively, and the amount of discharged slag was estimated at $34.7 \mathrm{~kg}$-slag/THM. In the conventional dephosphorization process, the amounts of charged fluxes and discharged slag in the second charge are the same as thosetin the first charge; therefore, for comparison with the case of residue recycling, the reference values of the amounts of charged fluxes and discharged slag were set at $65.0 \mathrm{~kg}-\mathrm{FeO} / \mathrm{THM}$, $31.8 \mathrm{~kg}-\mathrm{CaO} / \mathrm{THM}$, and $69.3 \mathrm{~kg}$-slag/THM, respectively. Furthermore, the amount of $\mathrm{Fe}(\mathrm{l})$ that was reduced from $\mathrm{FeO}$ and transferred from slag to hot metal in a series of oxidation reaction was $20.4 \mathrm{~kg}-\mathrm{Fe} / \mathrm{THM}$, and the total amount of phosphorus, silicon, manganese, and carbon removed from hot metal as per the oxidation reactions of Eqs. (1) to (4) was calculated at $5.2 \mathrm{~kg} / \mathrm{THM}$ (P: $1.0 \mathrm{~kg}-\mathrm{P} / \mathrm{THM}, \mathrm{Si}$ : $1.5 \mathrm{~kg}-\mathrm{Si} / \mathrm{THM}, \mathrm{Mn}: 0.7 \mathrm{~kg}-\mathrm{Mn} / \mathrm{THM}$, and C: $2.0 \mathrm{~kg}-\mathrm{C} /$ THM). In other words, the amount of hot metal increased by $15.2 \mathrm{~kg} / \mathrm{THM}(=20.4-5.2)$ before and after the dephosphorization treatment. However, this increment was so small - approximately $1.5 \%$ for 1 ton of hot metal - that it was assumed that variation in the amount of hot metal could be ignored in this study.

The composition of the residual slag and the mass ratio of the residual slag to initial slag are shown in Table 3 . The amount of slag generated from the first charge, which would be used for magnetic separation, was found to be $34.7 \mathrm{~kg}$-slag/THM; therefore, the amount of residual slag generated after magnetic separation was estimated at $21.8 \mathrm{~kg}$-residue/THM, which was $62.8 \%$ of the amount of discharged slag.

Table 4. Calculation results for the recycling effect of residual slag after hot metal dephosphorization process on $\mathrm{FeO}$ and $\mathrm{CaO}$ inputs and slag generation.

\begin{tabular}{|c|c|c|c|c|}
\hline & & (a) conventional process & (b) proposed process & (b)-(a) \\
\hline \multirow{3}{*}{$\begin{array}{c}2 \text { charges } \\
\text { total }\end{array}$} & $\mathrm{FeO}$ input & 65.0 & 67.7 & +2.7 \\
\hline & $\mathrm{CaO}$ input & 31.8 & 27.5 & -4.3 \\
\hline & slag generation & 69.4 & 45.8 & -23.6 \\
\hline \multirow{3}{*}{$\begin{array}{l}\text { average } \\
\text { per unit } \\
\text { charge }\end{array}$} & FeO input & 32.5 & 33.9 & +1.4 \\
\hline & $\mathrm{CaO}$ input & 15.9 & 13.8 & -2.1 \\
\hline & slag generation & 34.7 & 22.9 & -11.8 \\
\hline
\end{tabular}


Table 5. Effect of entrainment ratio of P-phase in the residual slag on the amount of slag generation and required flux inputs in the proposed process.

\begin{tabular}{|c|c|c|c|c|c|c|c|c|c|c|c|c|c|c|c|}
\hline \multirow{2}{*}{$\begin{array}{l}\text { Entrainment } \\
\text { ratio of } P \text { phase } \\
\text { in the residual } \\
\text { slag, } \varepsilon(\%)\end{array}$} & \multirow{2}{*}{$\begin{array}{l}\text { ratio against } \\
\text { initial } \\
\text { M phase }(\%)\end{array}$} & \multicolumn{5}{|c|}{ residual slag } & & \multicolumn{8}{|c|}{ dephosphorization of 2 nd charge by using residual slag } \\
\hline & & \multicolumn{6}{|c|}{ composition (mass\%) } & \multicolumn{5}{|c|}{ composition (mass\%) } & \begin{tabular}{|c|} 
slag \\
generation \\
$(\mathrm{kg} / \mathrm{THM})$
\end{tabular} & \multicolumn{2}{|c|}{ flux input (kg/THM) } \\
\hline 40 & \multirow{3}{*}{92} & 26.2 & 4.4 & 39.1 & 17.3 & 3.7 & 8.1 & 31.8 & 37.9 & 15.2 & 4.3 & 3.8 & 22.9 & 35.1 & 11.6 \\
\hline 30 & & 28.7 & 3.6 & 37.0 & 16.3 & 4.1 & 8.9 & 31.4 & 37.7 & 15.1 & 4.7 & 4.1 & 21.3 & 33.9 & 11.4 \\
\hline 20 & & 31.8 & 2.7 & 34.5 & 15.2 & 4.5 & 9.8 & 30.9 & 37.6 & \begin{tabular}{|l|l|}
15.0 \\
\end{tabular} & 5.0 & 4.5 & 19.6 & 32.7 & 11.3 \\
\hline
\end{tabular}

Calculation results for the recycling effect of residual slag are shown in Table 4. As the calculations described above were based on the amounts of two charges of hot metal, the final amounts of charged $\mathrm{FeO}$ and $\mathrm{CaO}$ and of discharged slag are also indicated as average values per charge. With regard to the magnetic separation experiment reported in a previous paper, ${ }^{7)}$ when the residual slag (shown in Table 3) discharged from the experiment was recycled, the amounts of charged $\mathrm{CaO}$ and discharged slag were decreased, although the amount of $\mathrm{FeO}$ charged to compensate for the decrease in oxidizing power increased slightly. The reduced amount was $11.8 \mathrm{~kg}$-slag/THM, and the reduction ratio to the normal dephosphorization process was $34 \%$.

The effect of reduction on the amounts of charged fluxes and slag discharged by residue recycling depends on the efficiency of the preceding magnetic separation. Therefore, the residue recycling effect in the case where recovery efficiency of phosphorus in the magnetic separation would be improved was calculated using the same procedure. First, based on the experimental results of magnetic separation reported in the previous paper, the residual slag compositions were set under the following conditions: (A) the amount of $\mathrm{FeO}-\mathrm{CaO}-\mathrm{SiO}_{2}(-\mathrm{MnO}-\mathrm{MgO})$-based $\mathrm{M}$ phase (Table 1) contained in the residue is assumed constant, i.e., $92 \%$ of the amount of $\mathrm{M}$ phase is present in the initial slag and $(\mathrm{B})$ the ratio of phosphorus remaining in the residue is set to be decreased by every $10 \%$ from the case where $\varepsilon$ is equal to $40 \%$. The compositions of each residual slag are shown in Table 5. The amounts of charged fluxes and discharged slag when each residual slag was recycled were calculated using the same procedure, and the obtained results are shown in Fig. 4. While the amount of added $\mathrm{CaO}$ was almost constant because the amount of $\mathrm{CaO}$ contained in the residual slag depended on the composition of the $\mathrm{M}$ phase, the amount of charged $\mathrm{FeO}$ decreased with the residual rate of the $\mathrm{P}$ phase, $\varepsilon$. At all separation ratios, the amounts of discharged slag were greatly reduced as compared to the case with no residue recycling. In particular, when the residual rate of the $\mathrm{P}$ phase was equal to $10 \%$, the reduced ratio of the amount of discharged slag reached as high as $48 \%$.

Recovery of the P phase from dephosphorization slag is important for the issue of securing new phosphorus resources. In addition to that, it was quantitatively demonstrated that the recycling of residual slag resulted in reduction in the amounts of charged fluxes used for hot metal treatment and reduction in the amount of discharged slag.

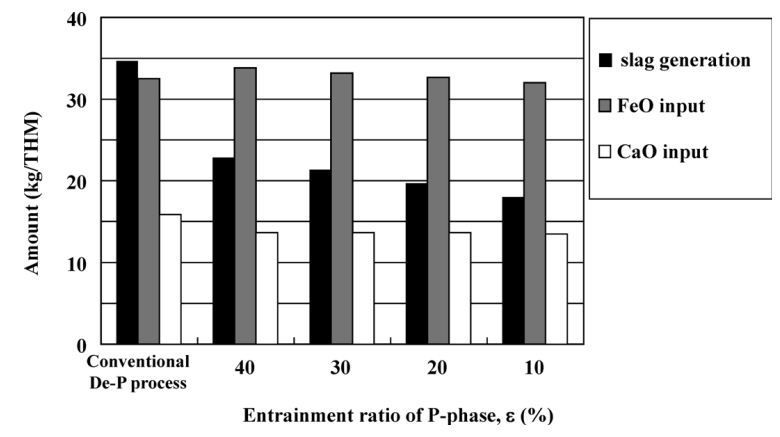

Fig. 4. Reduction in slag generation achieved by the recycling of residual slag after the magnetic separation of dephosphorization slag for phosphorus recovery. ${ }^{5,7}$

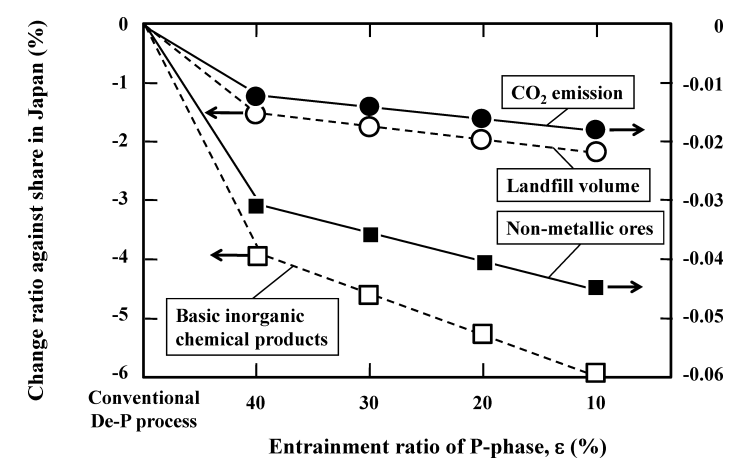

Fig. 5. Effect of phosphorus recovery from hot metal dephosphorization slag and recycling of residual slag on some economic activities in Japan, calculated by the Waste Input-Output model, ${ }^{5,9,10)}$ where e denotes the entrainment ratio of P-phase in the residual slag. Units of $\mathrm{CO}_{2}$ emission and landfill volume are ton- $\mathrm{CO}_{2}$ and $\mathrm{m}^{2}$, respectively, and those of non-metallic ores and basic inorganic chemical products are both expressed in million Japanese Yen.

\subsection{Ripple Effect of Phosphorus Recovery from Slag and Residue Recycling}

A previous paper ${ }^{5}$ analyzed the ripple effect in the case where phosphorus enriched phase recovered from dephosphorization slag was provided to the fertilizer and chemical industries as a substitute for phosphate rock. In addition, as shown in this study, it is expected that recycling the residue of phosphorus recovery would result in reduction in the required amounts of charged fluxes discharged slag and also would have a marked influence on the operations of the steel industry itself. Based on the findings obtained in this study, we analyzed the economic ripple effect and the results of reducing environmental loads by using the waste input-output model $^{9,10)}$ on the assumption that phosphorus 
recovery from slag and residue recycling are feasible. The following points were assumed for calculations.

1. $60 \%$ of the $\mathrm{P}$ phase and $8 \%$ of the $\mathrm{M}$ phases can be recovered as phosphorus resources.

2. The composition and monetary value of phosphorus resources recovered from dephosphorization slag are equal to that of phosphate rock.

3. Domestic transportation of the recovered phosphorus is offset by the decrease in transportation resulting from a reduction in the amount of imported phosphate rock; therefore additional transportation costs are not incurred.

4. Manufacturing processes of phosphoric acid do not need to change when recovered phosphorus is used as a constituent.

5. Costs arising from construction and operation of new infrastructural equipment, such as magnetic separation facilities, can be ignored.

Under the assumptions described above, the ripple effect on almost all-approximately 400-industrial sectors in Japan, as covered in the input-output table, was analyzed.

The results of model calculations indicate decreases in consumption and waste generation in many sectors. Figure 5 shows changes in the whole of Japan in four sectors: the ceramic raw-material minerals sector (lime and phosphate rock); inorganic chemical products; $\mathrm{CO}_{2}$ emissions; and the amount of final disposal (landfill volume) where the largest ripple effects of all were observed. Production activities in the ceramic raw-material minerals sector decreased remarkably by applying the proposed process. For example, when the residual rate of the $\mathrm{P}$ phase in the residue from the magnetic separation process is $10 \%$, the ceramic raw-material minerals sector showed great decrease (as much as $-6 \%$ ) due to subtraction resulting from reduction in the amount of imported phosphate rock. This corresponded to approximately 9.1 billion yen. Reduction effects on $\mathrm{CO}_{2}$ emissions and landfill volumes were also significant: when $\varepsilon=40 \%$, $\mathrm{CO}_{2}$ emissions were $-0.013 \%\left(-38 \mathrm{kt}-\mathrm{CO}_{2}\right.$ in terms of weight of $\mathrm{CO}_{2}$ ) and the amount of final disposal was -1.56 $\%\left(-10310 \mathrm{~m}^{3}\right.$ in terms of volume). If the residual rate of the $\mathrm{P}$ phase can be improved to $10 \%, \mathrm{CO}_{2}$ emissions are estimated at $-0.018 \%\left(-54 \mathrm{kt}-\mathrm{CO}_{2}\right)$ and the amount of final disposal is estimated at $-2.21 \%\left(-14619 \mathrm{~m}^{3}\right)$. It was shown that as the residual rate of the $\mathrm{P}$ phase in the residue decreases - in other words, as the phosphorus recovery rate from the dephosphorization slag is improved - the reduction effect is large. As described above, it is clear that using this technique will reduce environmental loads. As the efficiency of magnetic separation is improved, these effects will be enhanced.

\section{Conclusions}

Based on mass balance, we quantitatively evaluated the effect of reduction on the amounts of charged fluxes and the amount of discharged slag produced in the case where residual slag after phosphorus recovery (from hot-metal dephosphorization slag via the magnetic separation technique) was recycled as a raw material of fluxes used in the hotmetal dephosphorization process. Moreover, using a waste input-output table, we analyzed the economic ripple effect and the potential reduction in environmental loads of phosphorus recovery and residual slag recycling that may be achieved by introducing the magnetic separation technique. We reached the following conclusions.

(1) Recycling of residual slag for dephosphorization processes could result in reduction in the amount of charged $\mathrm{CaO}$ and the amount of discharged slag. When the residual rate of phosphorus in residual slag was $40 \%$ or less, the amount of charged $\mathrm{FeO}$ could be also reduced.

(2) It is expected that as phosphorus concentration in the phosphorus enriched phase phase is high, the amounts of $\mathrm{FeO}$ and $\mathrm{CaO}$ charges and the subsequent amount of discharged slag will be reduced; it is therefore important to investigate the conditions under which phosphorus concentration in dephosphorization slag will be enhanced, in the interests of securing phosphorus resources of high quality and reducing the numbers of charged fluxes and amounts of discharged slag.

(3) This technique is especially effective for reducing the amount of charged resources such as lime and phosphate rock, $\mathrm{CO}_{2}$ emissions, and landfill volume.

\section{Acknowledgments}

The authors are deeply grateful to members of the study group of multi-phase flux, the Iron and Steel Institute of Japan (Chairman: Dr. Fumitaka Tsukihashi, Professor of the University of Tokyo), for their beneficial advice and to Mr. Shota Irie (Graduate School of Environmental Studies, Tohoku University). This research was supported in part by a Contract Research Program "The Study on Sustainable Society" of Research Institute of Science and Technology for Society, the Japan Science and Technology Agency (RISTEX-JST), and by Grants-in-Aid for Scientific Research (Basic Research B, No. 18360433) for FY 2006 to FY 2008 from the Ministry of Education, Culture, Sports, Science and Technology; the authors wish to express their gratitude to these organizations.

\section{REFERENCES}

1) P. H. Abelson: Science, 283 (1999), 2015

2) K. Christen: Environ. Sci. Technol., 41 (2007), 2078.

3) H. Kubo, K. Yokoyama, K. Nakajima, S. Hashimoto and T. Nagasaka: J. Env. Eng. Manag., 18 (2008), 47.

4) K. Matsubae, H. Kubo, H. Ohtake and T. Nagasaka: Sociotechnica, 5 (2008), 106

5) K. Yokoyama, H. Kubo, K. Mori, H. Okada, S. Takeuchi and T. Nagasaka: ISIJ Int., 47 (2007), 1541.

6) T. Futatsuka, K. Shitogiden, T. Miki, T. Nagasaka and M. Hino: ISIJ Int., 44 (2004), 753.

7) H. Kubo, K. Matsubae-Yokoyama and T. Nagasaka: ISIJ Int., 50 (2010), 59

8) Nippon Slag Association ed.: Statistics Yearbook of Iron and Steel Slag for 2007, (2007).

9) S. Nakamura and Y. Kondo: J. Indust. Eco., 6 (2002), No. 1, 39

10) K. Yokoyama, T. Nagasaka and S. Nakamura: Ferrum, 10 (2005), 862.

11) K. Yokoyama, H. Kubo, K. Nakajima, Y.-S. Jeong and T. Nagasaka: Proc. 3rd Int. Conf. Process Develop. Iron Steelmaking (Scanmet III), June 2008, Lulea, Sweden, MEFOS, (2008), 551.

12) Y.-S. Jeong, K. Matsubae-Yokoyama, H. Kubo, J.-J. Pak and T. Nagasaka: Resour. Conserv. Recycl., 53 (2009), 479.

13) Y. Ogawa, M. Yano, S. Kitamura and H. Hirata: Tetsu-to-Hagané, 87 (2001), 21 